\title{
Energy Expenditure of Daily Living Activities in 3- to 6-Year-Old Children
}

\author{
Wonwoo Byun, Allison Barry, and Jung-Min Lee
}

\begin{abstract}
Background: There has been a call for updating the Youth Compendium of Energy Expenditure (YCEE) by including energy expenditure (EE) data of young children (ie, <6-year-old children). Therefore, this study examined the activity EE in 3 to 6 year old children using indirect calorimetry. Methods: Using Oxycon Mobile portable indirect calorimetry, both the oxygen consumption $\left(\mathrm{VO}_{2}\right)$ and the EE of 28 children (Girls: 46\%, Age: $4.8 \pm 1.0$, BMI: $16.4 \pm 1.6$ ) were measured while they performed various daily living activities (eg, watching TV, playing with toys, shooting baskets, soccer). Results: Across physical activities, averages of $\mathrm{VO}_{2}\left(\mathrm{ml} \cdot \mathrm{kg} \cdot \mathrm{min}^{-1}\right), \mathrm{VO}_{2}\left(\mathrm{~L} \cdot \mathrm{min}^{-1}\right)$, and $\mathrm{EE}$ ranged from $8.9 \pm 1.5$ to $33.3 \pm 4.8 \mathrm{ml} \cdot \mathrm{kg} \cdot \mathrm{min}{ }^{-1}$, from $0.17 \pm$ 0.04 to $0.64 \pm 0.16 \mathrm{~L} \cdot \mathrm{min}^{-1}$, and from $0.8 \pm 0.2$ to $3.2 \pm 0.7 \mathrm{kcal} \cdot \mathrm{min}^{-1}$, respectively. Conclusions: These findings will contribute to the upcoming YCEE update.
\end{abstract}

Keywords: physical activity, measurement, pediatrics, youth, public health

Physical Activity (PA) has been recognized as an important behavior for reversing the childhood obesity epidemic. ${ }^{1}$ In PA and public health research, efforts to improve the accuracy of PA measurements are greatly warranted as surveillances and promotions of PA require the utilization of accurate PA assessments. ${ }^{2}$ Compendium of PA is a known method to estimate energy expenditure (EE). ${ }^{3}$ In 2008, the Youth Compendium of Energy Expenditure (YCEE) was developed to standardize EE values of various PAs, expressed as Metabolic Equivalent (MET), in children ages 6 to 18 years. ${ }^{4}$ Although it has been widely used in research, the validity of the current version of YCEE is diminished by limited data (ie, small sample sizes, no data for $<6$ years old) and MET values based on adult data; thus there is a need for an update by including studies with fresh data, <6-year-old children data, and larger sample sizes. Therefore, the purpose of this study was to examine the activity energy expenditure using indirect calorimetry in 3- to 6-year-old children.

\section{Methods}

\section{Participants}

Twenty-eight 3- to 6-year-old children (Girls: 46\%, Age: $4.8 \pm 1.0$, BMI: $16.4 \pm 1.6$ ) took part in this study. Before data collection, parents or guardians signed a written informed consent to allow their child to participate in this study. The Institutional Review Board at North Dakota State University approved this study.

\section{Activities}

Each participant reported to the laboratory and completed an activity protocol consisting of 6 different bouts of daily living activities

Byun (w.byun@ndsu.edu) and Barry are with the Dept of Health, Nutrition, and Exercise Sciences; Byun is also with the Dept of Public Health; North Dakota State University. Lee is with the School of Health, Physical Education, and Recreation, University of Nebraska at Omaha.
(DLA) across sedentary, light, moderate, and vigorous intensity levels. DLA were carefully selected based on following criteria: 1) age-appropriate activities for 3- to 6-year-old children, 2) popular activities in free-living settings (ie, childcare and home), and 3) activities for which children need minimal instruction. Participants were instructed to wear a portable indirect calorimetry (Oxycon Mobile) while they performed a variety of DLA. Following Welk's recommendations, all activities progressed from sedentary to increasingly vigorous intensity. ${ }^{5}$

Research assistants performed all activities alongside the children to maintain motivation levels, as well as to insure children stayed engaged in every activity at light, moderate, and hard efforts. The assistants were allowed to give positive verbal feedback to encourage the children to complete each activity. Each activity bout was 5-minutes long, except for the sedentary activities, which lasted 4 minutes apiece. The total duration of each session was 34 minutes, including a 1-minute transition period between each activity bout.

Sedentary Activities. Sedentary activities included

$T V$ watching-lying down. Children lay in the supine position on a cushioned mat while watching an age-appropriate movie.

$T V$ watching_-sitting in a chair. Children sat in a child-sized chair while watching an age-appropriate movie.

Physical Activities. Physical activities included

Playing with small toys. On a rubber floor, children played with a variety of toys that do not require moderate-to-hard efforts (eg, building blocks, miniature cars, stuffed animals, and puzzles).

Walking/exploring. Children participated in a scavenger hunt in which they quickly walked around the laboratory to find hidden toys. These activities led to sporadic running and required children's light-to-moderate efforts.

Soccer/Running. Children kicked a soccer ball into a net, chased after it, and raced with the assistant.

Basketball/Throwing into a net. Children dribbled and shot a basketball using a 4-ft hoop or threw a rubber ball against 
a Tchoukball (throwing) net. The children also chased rebounded balls. These activities required continuous running and jumping at children's moderate-to-hard efforts.

\section{Measurements}

Indirect Calorimetry. The Oxycon Mobile (Viasys Healthcare Inc., Yorba Linda, CA USA), a lightweight (950 g), portable indirect calorimetry system, was used to assess EE. Each participant was fitted with a harness that held the data exchange (DEX) and analyzer (SBx) units on the child's back. The participant was also fitted with a flexible pediatric mask that covered the participant's nose and mouth (Hans Rudolph Inc., Kansas City, MO) held in place by a head harness. A bidirectional rotary flow and measurement sensor (Triple V) was attached to the mask and SBx unit. A Nafion sampling tube ran from the Triple $\mathrm{V}$ to the $\mathrm{SBx}$ unit to analyze the composition of $\mathrm{O}_{2}$ and $\mathrm{CO}_{2}$ in the expired air. Before each trial, flow-volume and gas calibrations using the reference gas $(16 \%$ $\mathrm{O}_{2}$ and $4 \% \mathrm{CO}_{2}$ ) were performed according to the manufacture's guidelines. Breath-by-breath measures of oxygen consumption $\left(\mathrm{VO}_{2}\right)$, carbon dioxide $\left(\mathrm{VCO}_{2}\right)$, and minute ventilation $(\mathrm{VE})$ were averaged into minute-by-minute values, and $\mathrm{EE}$ during the activities were summarized as $\mathrm{kcal} \cdot \mathrm{min}^{-1}$. Data during the transition period and the first $1 \mathrm{~min}$ of each activity were not included in the analysis. The validity of Oxycon Mobile was determined in a recent study that measures of metabolic parameters $\left(\mathrm{VO}_{2}, \mathrm{VCO}_{2}\right.$, and $\left.\mathrm{VE}\right)$ were similar between the Oxycon Mobile and the Douglas bag method. ${ }^{6}$

Demographic and Anthropometric Measurements. A parent or guardian using a short survey reported each child's age, gender, and race/ethnicity. Anthropometric measures were obtained before the start of EE measurements. Body weight was measured to the nearest $0.1 \mathrm{~kg}$ using a stadiometer and height was measured to the nearest $1 \mathrm{~mm}$ using an electronic scale, after the child removed shoes and outer clothing. To ensure reliability, weight and height were measured twice; if the first 2 measurements differed by more than $1 \mathrm{~cm}$ or $1 \mathrm{~kg}$, respectively, another measurement was taken. BMI was calculated as weight divided by height squared $\left(\mathrm{kg} \cdot \mathrm{m}^{-2}\right)$. BMI percentile was calculated based on the population mean BMI values reported in the CDC growth charts. ${ }^{7}$

\section{Analysis}

Descriptive statistics (mean, standard deviation (SD), minimum, and maximum) for the estimates of $\mathrm{VO}_{2}\left(\mathrm{ml} \cdot \mathrm{kg} \cdot \mathrm{min}^{-1}\right), \mathrm{VO}_{2}\left(\mathrm{~L} \cdot \mathrm{min}^{-1}\right)$, and $\mathrm{EE}$ were calculated by age and gender. Gender differences in all estimates were tested using independent $t$ tests. For all statistical analyses, the SAS statistical program, version 9.3 (SAS Institute, Cary, NC, USA) was used and the statistical significance was set at $\alpha=.05$.

\section{Results}

As shown in Table 1, age, weight, height, and BMI of children were similar between boys and girls ( $P$ for difference $>.05)$. Metabolic parameters and EE of sedentary activities are presented in Table 2. During the TV watching, measures of $\mathrm{VO}_{2}$ and $\mathrm{EE}$ were similar between lying down and sitting positions: $\mathrm{VO}_{2}\left(\mathrm{ml} \cdot \mathrm{kg} \cdot \mathrm{min}^{-1}\right)($ lying down: $8.9 \pm 1.5 \mathrm{ml} \cdot \mathrm{kg} \cdot \mathrm{min}^{-1}$ vs. sitting: $\left.9.0 \pm 1.7 \mathrm{ml} \cdot \mathrm{kg} \cdot \mathrm{min}^{-1}\right)$, $\mathrm{VO}_{2}\left(\mathrm{~L} \cdot \mathrm{min}^{-1}\right)$ (lying down: $0.17 \pm 0.04 \mathrm{~L} \cdot \mathrm{min}^{-1} \mathrm{vs}$. sitting: $0.17 \pm$ $0.04 \mathrm{~L} \cdot \mathrm{min}^{-1}$ ), and $\mathrm{EE}$ (lying down: $0.8 \pm 0.2 \mathrm{kcal} \cdot \mathrm{min}^{-1}$ vs. sitting: $\left.0.8 \pm 0.2 \mathrm{kcal} \cdot \mathrm{min}^{-1}\right)$. Across physical activities, averages of $\mathrm{VO}_{2}$ $\left(\mathrm{ml} \cdot \mathrm{kg} \cdot \mathrm{min}^{-1}\right), \mathrm{VO}_{2}\left(\mathrm{~L} \cdot \mathrm{min}^{-1}\right)$, and $\mathrm{EE}$ ranged from $14.9 \pm 3.6$ to $33.3 \pm 4.8 \mathrm{ml} \cdot \mathrm{kg} \cdot \mathrm{min}^{-1}$, from $0.28 \pm 0.07$ to $0.64 \pm 0.16 \mathrm{~L} \cdot \mathrm{min}^{-1}$, and from $1.4 \pm 0.3$ to $3.2 \pm 0.7 \mathrm{kcal} \cdot \mathrm{min}^{-1}$, respectively (Table 3 ). Across activities, no statistically significant differences in metabolic parameters were found between age and gender.

\section{Discussion}

Several studies have used the indirect calorimetry method to examine the energy cost of sedentary and physical activities in school-age children and youth, 8,9 but very few studies estimated EE of those activities in preschool-age children. To our knowledge, this is the first to describe the EE of DLA using indirect calorimetry in 3- to 6-year-old children. ${ }^{4}$ Overall, there was no significant difference in activity EEs between boys and girls. When compared with EE values for older children in the current YCEE, we found that the estimates of EE in young children was higher for sedentary activities (eg, watching TV-lying down: $2.5 \mathrm{METs}\left(8.9 \mathrm{ml} \cdot \mathrm{kg} \cdot \mathrm{min}^{-1}\right)$ vs. 1.1 METs), but lower for activities at vigorous intensity (eg, soccer: 9.5 METs (33.3 $\left.\mathrm{ml} \cdot \mathrm{kg} \cdot \mathrm{min}^{-1}\right)$ vs. 11.0 METs).

Findings from this study have several important implications especially for the development of updated YCEE. First, approximately two-thirds of EE values in the current YCEE were derived based on adults MET values, thus the different EE values between younger (our sample) and older children (the YCEE) suggest that extrapolations of adults EE values to estimate EE in children should be discouraged in the updated YCEE. Second, the current YCEE provides EE values for children and youth aged 6 to 18 , but no data are available for assigning $\mathrm{EE}$ values for children under age 6. Thus, the observed EE values in this study will provide recent and accurate data to expand the age range of the updated YCEE.

Previous studies measured EE during structured locomotive activities (ie, walking and running on treadmill or ground), ${ }^{10}$ thus measures of EE while children performing DLA using indirect calorimetry is major strength of this study. Measuring activity EE in children and youth is challenging, particularly in very young children. Due to difficulties of wearing the mask and indirect calorimetry for long period of time, the 5-minute restriction for each activity bout (34 minutes total duration) was a limitation of this study.

In conclusion, we believe that findings from this study will significantly contribute to the development of an updated YCEE by providing the recent and accurate data on EE in young children.

\section{Acknowledgments}

We thank all participants and parents that participated in this investigation.

Table 1 Descriptive Characteristics of the Participants

\begin{tabular}{lcccccc}
\hline & $\mathbf{n}$ & Age $(\mathbf{y r})$ & Height $(\mathbf{c m})$ & Weight $(\mathbf{k g})$ & BMI $_{\left.\mathbf{( k g} \cdot \mathbf{m}^{-2}\right)}$ & BMI (percentile) \\
\hline Total & 28 & $4.8 \pm 1.0$ & $108.6 \pm 9.3$ & $19.4 \pm 3.4$ & $16.4 \pm 1.6$ & $66.0 \pm 27.0$ \\
Girls & 13 & $4.8 \pm 0.8$ & $108.2 \pm 6.5$ & $19.0 \pm 2.8$ & $16.2 \pm 1.7$ & $64.0 \pm 28.8$ \\
Boys & 15 & $4.9 \pm 1.2$ & $109.0 \pm 11.5$ & $19.7 \pm 3.9$ & $16.5 \pm 1.5$ & $67.7 \pm 26.2$ \\
\hline
\end{tabular}




\begin{tabular}{|c|c|c|c|c|c|c|c|}
\hline \multirow[b]{2}{*}{ Activity } & \multirow[b]{2}{*}{$\mathrm{n}$} & \multicolumn{2}{|c|}{$\mathrm{ml} \cdot \mathrm{kg} \cdot \mathrm{min}^{-1}$} & \multicolumn{2}{|c|}{$L \cdot \min ^{-1}$} & \multicolumn{2}{|c|}{$\mathrm{kcal} \cdot \mathrm{min}^{-1}$} \\
\hline & & Mean \pm SD & Min-Max & Mean \pm SD & Min-Max & Mean \pm SD & Min-Max \\
\hline TV watching (lying down) & 27 & & & & & & \\
\hline $3-6 y$ & 27 & $8.9 \pm 1.5$ & $6.7-12.2$ & $0.17 \pm 0.04$ & $0.10-0.26$ & $0.8 \pm 0.2$ & $0.5-1.2$ \\
\hline $3 y$ & 5 & $9.3 \pm 2.1$ & $7.1-11.7$ & $0.15 \pm 0.04$ & $0.10-0.21$ & $0.7 \pm 0.2$ & $0.5-1.0$ \\
\hline $4 y$ & 9 & $8.7 \pm 1.1$ & $6.7-9.3$ & $0.16 \pm 0.02$ & $0.12-0.19$ & $0.7 \pm 0.1$ & $0.6-0.9$ \\
\hline $5 \mathrm{y}$ & 9 & $8.8 \pm 1.9$ & $7.1-12.2$ & $0.18 \pm 0.04$ & $0.13-0.23$ & $0.9 \pm 0.2$ & $0.6-1.1$ \\
\hline $6 y$ & 4 & $9.2 \pm 1.2$ & $8.1-10.7$ & $0.20 \pm 0.04$ & $0.17-0.26$ & $1.0 \pm 0.1$ & $0.8-1.2$ \\
\hline Girls & 13 & $8.7 \pm 1.6$ & $6.7-11.7$ & $0.16 \pm 0.03$ & $0.11-0.22$ & $0.8 \pm 0.2$ & $0.5-1.1$ \\
\hline Boys & 14 & $9.2 \pm 1.5$ & $7.3-12.2$ & $0.18 \pm 0.04$ & $0.12-0.26$ & $0.8 \pm 0.2$ & $0.6-1.2$ \\
\hline TV watching (sitting) & 28 & & & & & & \\
\hline $3-6 y$ & 28 & $9.0 \pm 1.7$ & $6.1-13.4$ & $0.17 \pm 0.04$ & $0.11-0.25$ & $0.8 \pm 0.2$ & $0.6-1.2$ \\
\hline $3 y$ & 5 & $10.3 \pm 2.3$ & $7.1-11.7$ & $0.16 \pm 0.05$ & $0.11-0.22$ & $0.8 \pm 0.2$ & $0.6-1.1$ \\
\hline $4 y$ & 9 & $8.7 \pm 1.5$ & $6.1-10.4$ & $0.17 \pm 0.02$ & $0.12-0.19$ & $0.7 \pm 0.1$ & $0.6-0.9$ \\
\hline $5 \mathrm{y}$ & 10 & $8.7 \pm 1.6$ & $7.0-11.9$ & $0.18 \pm 0.03$ & $0.13-0.23$ & $0.9 \pm 0.2$ & $0.6-1.1$ \\
\hline $6 y$ & 4 & $9.1 \pm 1.0$ & $8.1-10.5$ & $0.20 \pm 0.03$ & $0.17-0.25$ & $1.0 \pm 0.2$ & $0.8-1.2$ \\
\hline Girls & 13 & $8.5 \pm 1.6$ & $6.1-11.4$ & $0.16 \pm 0.03$ & $0.12-0.21$ & $0.8 \pm 0.2$ & $0.6-1.0$ \\
\hline Boys & 15 & $9.5 \pm 1.6$ & $7.4-13.4$ & $0.18 \pm 0.04$ & $0.13-0.25$ & $0.9 \pm 0.2$ & $0.6-1.2$ \\
\hline
\end{tabular}

Note. $\mathrm{ml} \cdot \mathrm{kg} \cdot \mathrm{min}^{-1}=$ milliliters (of oxygen) per kilogram body weight; $\mathrm{L} \cdot \mathrm{min}^{-1}=$ liters (of oxygen) per minute.

Table 3 Energy Expenditure by Activities

\begin{tabular}{|c|c|c|c|c|c|c|c|}
\hline \multirow[b]{2}{*}{ Activity } & \multirow[b]{2}{*}{$\mathrm{n}$} & \multicolumn{2}{|c|}{$\mathrm{ml} \cdot \mathrm{kg} \cdot \mathrm{min}^{-1}$} & \multicolumn{2}{|c|}{$L \cdot \min ^{-1}$} & \multicolumn{2}{|c|}{$\mathrm{kcal} \cdot \mathrm{min}^{-1}$} \\
\hline & & Mean \pm SD & Min-Max & Mean \pm SD & Min-Max & Mean \pm SD & Min-Max \\
\hline $\begin{array}{l}\text { Playing with toys (ie, } \\
\text { blocks, cars, puzzle) }\end{array}$ & 28 & & & & & & \\
\hline $3-6 y$ & 28 & $14.9 \pm 3.6$ & $7.7-28.1$ & $0.28 \pm 0.07$ & $0.18-0.47$ & $1.4 \pm 0.3$ & $0.9-2.3$ \\
\hline $3 y$ & 5 & $15.6 \pm 2.4$ & $13.0-18.2$ & $0.24 \pm 0.06$ & $0.19-0.33$ & $1.2 \pm 0.3$ & $1.0-1.6$ \\
\hline $4 y$ & 9 & $15.8 \pm 5.5$ & $7.7-28.1$ & $0.28 \pm 0.08$ & $0.19-0.48$ & $1.3 \pm 0.4$ & $0.9-2.3$ \\
\hline $5 \mathrm{y}$ & 10 & $13.5 \pm 2.3$ & $9.7-16.8$ & $0.28 \pm 0.06$ & $0.18-0.37$ & $1.4 \pm 0.3$ & $0.9-1.8$ \\
\hline $6 y$ & 4 & $15.6 \pm 0.8$ & $14.6-16.5$ & $0.35 \pm 0.04$ & $0.29-0.39$ & $1.5 \pm 0.2$ & $1.4-1.8$ \\
\hline Girls & 13 & $13.8 \pm 3.1$ & $7.7-18.2$ & $0.26 \pm 0.05$ & $0.18-0.33$ & $1.2 \pm 0.2$ & $0.9-1.6$ \\
\hline Boys & 15 & $15.9 \pm 3.8$ & $11.7-28.1$ & $0.31 \pm 0.08$ & $0.20-0.48$ & $1.5 \pm 0.4$ & $1.0-2.3$ \\
\hline $\begin{array}{l}\text { Walking/exploring, } \\
\text { scavenger hunt }\end{array}$ & 28 & & & & & & \\
\hline $3-6 y$ & 28 & $23.5 \pm 4.8$ & $15.6-36.8$ & $0.45 \pm 0.09$ & $0.18-0.48$ & $2.2 \pm 0.5$ & $1.4-3.0$ \\
\hline $3 y$ & 5 & $24.7 \pm 2.7$ & $28.8-38.1$ & $0.39 \pm 0.13$ & $0.29-0.62$ & $3.1 \pm 0.4$ & $2.4-3.7$ \\
\hline $4 \mathrm{y}$ & 9 & $24.2 \pm 6.3$ & $15.6-36.8$ & $0.43 \pm 0.08$ & $0.36-0.62$ & $2.1 \pm 0.4$ & $1.8-3.0$ \\
\hline $5 \mathrm{y}$ & 10 & $21.9 \pm 3.5$ & $16.8-28.3$ & $0.46 \pm 0.09$ & $0.32-0.62$ & $2.2 \pm 0.5$ & $1.5-3.0$ \\
\hline $6 y$ & 4 & $24.5 \pm 1.6$ & $22.4-26.2$ & $0.54 \pm 0.05$ & $0.47-0.59$ & $2.6 \pm 0.3$ & $2.3-2.9$ \\
\hline Girls & 13 & $23.1 \pm 4.7$ & $15.6-34.6$ & $0.43 \pm 0.09$ & $0.31-0.62$ & $2.1 \pm 0.4$ & $1.5-3.0$ \\
\hline Boys & 15 & $23.9 \pm 5.0$ & $16.8-36.8$ & $0.46 \pm 0.11$ & $0.29-0.62$ & $2.3 \pm 0.5$ & $1.4-3.0$ \\
\hline Running, soccer & 28 & & & & & & \\
\hline $3-6 y$ & 28 & $33.3 \pm 4.8$ & $25.6-44.5$ & $0.64 \pm 0.15$ & $0.36-0.92$ & $3.2 \pm 0.7$ & $1.7-4.6$ \\
\hline $3 \mathrm{y}$ & 5 & $30.5 \pm 6.2$ & $26.4-41.0$ & $0.49 \pm 0.15$ & $0.36-0.73$ & $2.4 \pm 0.8$ & $1.7-3.7$ \\
\hline $4 y$ & 9 & $34.2 \pm 2.7$ & $28.8-38.1$ & $0.62 \pm 0.08$ & $0.48-0.73$ & $3.1 \pm 0.4$ & $2.4-3.7$ \\
\hline $5 y$ & 10 & $32.1 \pm 4.5$ & $25.6-37.7$ & $0.67 \pm 0.12$ & $0.51-0.92$ & $3.3 \pm 0.6$ & $2.5-4.6$ \\
\hline $6 y$ & 4 & $37.7 \pm 5.7$ & $30.5-44.5$ & $0.83 \pm 0.09$ & $0.72-0.90$ & $4.1 \pm 0.5$ & $3.5-4.5$ \\
\hline Girls & 13 & $33.6 \pm 4.8$ & $26.8-44.5$ & $0.63 \pm 0.10$ & $0.41-0.80$ & $3.1 \pm 0.5$ & $2.0-3.9$ \\
\hline Boys & 15 & $33.0 \pm 5.0$ & $25.6-38.1$ & $0.66 \pm 0.18$ & $0.36-0.93$ & $3.3 \pm 0.9$ & $\begin{array}{l}1.7-4.6 \\
\text { (continued) }\end{array}$ \\
\hline
\end{tabular}


Table 3 (continued)

\begin{tabular}{|c|c|c|c|c|c|c|c|}
\hline \multirow[b]{2}{*}{ Activity } & \multirow[b]{2}{*}{$\mathbf{n}$} & \multicolumn{2}{|c|}{$\mathrm{ml} \cdot \mathrm{kg} \cdot \mathrm{min}^{-1}$} & \multicolumn{2}{|c|}{$L \cdot \min ^{-1}$} & \multicolumn{2}{|c|}{$\mathrm{kcal} \cdot \mathrm{min}^{-1}$} \\
\hline & & Mean \pm SD & Min-Max & Mean \pm SD & Min-Max & Mean \pm SD & Min-Max \\
\hline $\begin{array}{l}\text { Dribble and shooting } \\
\text { basket, continuous ball } \\
\text { throwing to the net }\end{array}$ & 28 & & & & & & \\
\hline $3-6 y$ & 28 & $33.2 \pm 5.3$ & $22.9-43.3$ & $0.64 \pm 0.16$ & $0.33-0.97$ & $3.1 \pm 0.8$ & $1.6-4.8$ \\
\hline $3 y$ & 5 & $30.5 \pm 6.1$ & $22.9-36.5$ & $0.49 \pm 0.14$ & $0.34-0.65$ & $2.4 \pm 0.7$ & $1.6-3.2$ \\
\hline $4 y$ & 9 & $34.2 \pm 4.0$ & $30.0-43.3$ & $0.62 \pm 0.10$ & $0.48-0.78$ & $2.9 \pm 0.7$ & $1.7-3.9$ \\
\hline $5 \mathrm{y}$ & 10 & $31.7 \pm 5.3$ & $25.0-39.2$ & $0.66 \pm 0.14$ & $0.52-0.97$ & $3.3 \pm 0.7$ & $2.5-4.8$ \\
\hline $6 y$ & 4 & $38.3 \pm 4.7$ & $31.3-41.3$ & $0.85 \pm 0.12$ & $0.74-0.96$ & $4.2 \pm 0.6$ & $3.6-4.8$ \\
\hline Girls & 13 & $32.6 \pm 3.6$ & $27.7-41.3$ & $0.62 \pm 0.09$ & $0.19-0.78$ & $3.0 \pm 0.4$ & $2.4-3.9$ \\
\hline Boys & 15 & $33.7 \pm 6.5$ & $22.9-43.3$ & $0.67 \pm 0.20$ & $0.33-0.97$ & $3.2 \pm 1.1$ & $1.6-4.8$ \\
\hline
\end{tabular}

Note. $\mathrm{ml} \cdot \mathrm{kg} \cdot \mathrm{min}^{-1}=$ milliliters (of oxygen) per kilogram body weight; $\mathrm{L} \cdot \mathrm{min}^{-1}=$ liters (of oxygen) per minute.

\section{References}

1. Ogden CL, Carroll MD, Kit BK, Flegal KM. Prevalence of childhood and adult obesity in the United States, 2011-2012. JAMA. 2014;311:806-814. PubMed doi:10.1001/jama.2014.732

2. Bassett DR. Device-based monitoring in physical activity and public health research. Physiol Meas. 2012;33:1769-1783. PubMed doi:10.1088/0967-3334/33/11/1769

3. Ainsworth BE, Haskell WL, Herrmann SD, et al. 2011 Compendium of Physical Activities: a second update of codes and MET values. Med Sci Sports Exerc. 2011;43:1575-1581. PubMed doi:10.1249/ MSS.0b013e31821ece12

4. Ridley K, Ainsworth BE, Olds TS. Development of a compendium of energy expenditures for youth. Int J Behav Nutr Phys Act. 2008;5:45. PubMed doi:10.1186/1479-5868-5-45

5. Welk GJ. Principles of design and analyses for the calibration of accelerometry-based activity monitors. Med Sci Sports Exerc. 2005;37:S501S511. PubMed doi:10.1249/01.mss.0000185660.38335.de
6. Rosdahl H, Gullstrand L, Salier-Eriksson J, Johansson P, Schantz P. Evaluation of the Oxycon Mobile metabolic system against the Douglas bag method. Eur J Appl Physiol. 2010;109:159-171. PubMed doi:10.1007/s00421-009-1326-9

7. Kuczmarski RJ, Ogden CL, Guo SS, et al. CDC Growth Charts for the United States: methods and development. Vital Health Stat 11. 2000;246:1-190. PubMed

8. Lyden K, Keadle SK, Staudenmayer J, Freedson P, Alhassan S. Energy cost of common activities in children and adolescents. $J$ Phys Act Health. 2013;10:62-69. PubMed

9. Alhassan S, Lyden K, Howe C, Kozey Keadle S, Nwaokelemeh O, Freedson PS. Accuracy of accelerometer regression models in predicting energy expenditure and METs in children and youth. Pediatr Exerc Sci. 2012;24:519-536. PubMed

10. Pate RR, Almeida MJ, McIver KL, Pfeiffer KA, Dowda M. Validation and calibration of an accelerometer in preschool children. Obesity (Silver Spring). 2006;14:2000-2006. PubMed doi:10.1038/ oby. 2006.234 